\title{
Current Situation of Animation Design Talents Cultivation in Chinese Colleges and Universities
}

\author{
Luo lingxin \\ Nanchang Institute of Technology\&inform nanchang 330099, China
}

\begin{abstract}
With the rising trend of world's cartoon design industry in recent years, animation culture in many countries and regions carries out a new wave. As a result, the demand for animation industry talents is more and more urgent from various places. In particular, China's recent level of animation industry has a strong upgrade, making more stringent requirements for animation design talents in various colleges and universities. How to enhance our college animation design talents is discussed in this paper.
\end{abstract}

Key words: Chinese colleges and universities; Animation design

For the development of our country's future animation industry, animation major courses are scientifically and orderly conducted in various colleges and universities according to the discussion and research of Development and Reform Committee members, so that more students who do well in this area can actively learn all kinds of curriculum knowledge, and then use their own unique insight and imagination to open a more wonderful animation world. Then our Chinese animation industry culture will also get flourished, and gradually we can match with many famous animation works in the world.

\section{The present situation of Chinese college animation design talents}

According to current domestic animation industry development from a variety of well-known animation movies such as "Havoc in Heaven", "Kung Fu Panda" series, as well as Lunar New Year stalls "Radiant" cartoon, followed by the most heroic "Bear and Haunt" series, etc., there are more exaggerated styles to attract low-level children to watch, and their parents are also teaching some popular science under the influence. Such funny and educative animations have a certain bloom in various values, outlook on life, as well as the world view of people. Children and adults are sitting together to watch them. They can enjoy wonderful styles while having aesthetic education. In our college animation design majors, there are often such a situation that there are a lot of students with fine art skills and their hand-painted ability can even exceed mouse painting, but their story composing ability is relatively low. On the one hand, they can easily control the original painting, sub-lens, and character setting, but on the other side screenwriter talents are missing. As story's core planners, they should coordinate and command the entire animation. Such a soul central character needs our teachers' intentional training and creation. 


\section{Specific methods for animation design talent training in Chinese University}

Carry out professional courses in various fields. First of all, vast number of students comes to college and they have already made preparations for variety of hardships. In their favorite expertise areas, they tireless study and innovate. Students strive to learn professional knowledge----painting skills in good self-discipline and independent learning ability. They draw the best art works in their short college time, and let inspiration fly in their wisdom. With the help of various professional teachers, students begin to learn the content of various disciplines, including literary creation knowledge, and read a lot of writers' works. So their ability to compose stories may be gradually enhanced, and with their imagination, they can reasonably derive wonderful stories. Try to be a man who can write a story and happily paint out the story. Characters set and shape are arranged very emotional. According to story's development clues, hand-paint each sub-scenes, their fight scenes, and depict different scenes reasonably and scientifically.

Create animation workshop teaching model by teachers and students together .Innovative teaching model experiments can be appropriately carried out in the university----that is, teachers and several students together set up simulation workshop for a new created animation story work. They together complete such a team major work content and conduct a reasonable teaching experiment. They are trying to write and draw the entire animation story, and at the same time, they can also feel ahead of work state society experience. In the entire campus teaching, animation professional design talents can have scientific and orderly teaching activities. In a variety of animation industry works, students follow the pace of teachers and study pleasantly and vividly each animation with teaching significance. For example, some foreign animation industry's chain derived works----Disney animated series of works "Snow White and the Story of Seven Dwarfs", "Monster Shrek", "Lion King", "Clown Fish Nimo", "Cars", as well as new works in recent years, "Up" is full of warmth between grandfather and grandmother. Some early clay animation work "Mark Twain Adventure” and so on interprets anthropomorphic social sensibility in different ways. When animals are animated and given some talents' emotions and thoughts, the animated characters are set to have vitality and soul, and they seem to symbolize good qualities of mankind, such as Nimo, the clownfish, who left his father and mother and braved to risk, and finally overcame difficulties and their own feelings when they are timid and in growth. This in a sense is anthropomorphic story complex, and they tell us lovely young friends by their legendary life that each person in growth will encounter this or that difficulties, and difficulties are not terrible as long as we carefully overcome them and work hard forward to the bright future. One day we will grow up. At that time we have become very strong. The most rustic and simple doctrine of life is often inherent in the essence of animation, which is worthy for our young and old friends to watch once and once again.

Expand core creative competence of animation design talent.The most important guiding principle in the whole animation teaching field in college is: "innovation, because innovation is an inexhaustible motive force for national progress." Twenty-first century is next generation's world. Their minds and brain holes will 
become more incredible, and our animation industry also need to give full play to the effectiveness of advancing with the times and create more works suitable for the majority of students which are worth watching and thinking deeply. How can we find some creative inspiration in daily life? It has always been the difficult problem for the majority of professional animation talents. Students need to gradually nurture a delicate heart in their daily learning, form sensitivity to a variety of art forms, as well as perception ability of the world. They are able to refine all kinds of interesting things in life and through their own thinking and nurture, carefully create works full of beauty and interest. With writing ability exercise, students can write a humorous story script, and then according to the script, draw the original painting and sub-lens fragments, so that the characters setting and the story core would be consistent. Use characters language to depict profound story twists and turns, which is full of mystery and so on.

As an animation professional talent with a sense of temperature and interests, a good outlook on life, world outlook, values, and so on must be in composing and painting process, so that they can be rooted as the soul of the entire cartoon work, which is the bones need to be deeply rooted, and then use a variety of effective artistic expression forms for the animation story deep processing. Each character is given a variety of different names and characters, and use flashback way for the story's main line, so that it would be hidden in the story but always running through it. Finally with art display, all lifelike roles are vividly presented and they begin to interpret the entire animation. All the scenes and people are in place, our masters of the story begin to invite hand-paint masters to use colorful and exaggerated lines to interpret the entire animation taste, vividly demonstrate each unique characteristic in the animation. Mouse painting is high-end rendering of CG personnel to make the whole script becomes alive as same as cartoon, which is the most beautiful place in animation and the attracting point of the crowd. Learn major foreign animation teams' professionalism and professional level so that their essence slowly penetrates into the hearts of our animation professionals.

\section{Far-reaching significance for animation design talent training in Chinese colleges and universities}

From the setup of a series of workshops to the completion of the script and story picture books, teachers and professional animation talents are powerful alliances to work together making a new wave in animation industry. Their ability for deep-level mining captures the source of the story. Arts come from life in general, but they are also generally higher than life. They are the most advanced forms of trivia in life. Animation professionals need to polish up their art drawing skills and can portray all kinds of inspiration handily. They need fast and accurate expression. They will do better because of animation professional tribute because they love these warm pictures. Their tireless spirit and unlimited vision and expectations for animation industry will make their dream come true, which is that one day their drawn story script can be on the large screen in the country and their light of wisdom may illuminate every corner of the country. Kids can rejoice in watching them and from 
which get some inspiration of life, so as to encourage them to grow better. This is the ultimate meaning of professional animation genius struggles. Their mental work is in exchange for many children and older friends praises, which for sure is of the greatest significance for them. And they make some useful contributions for our country's animation industry too.

\section{Conclusion}

In summary, the present situation in animation professional talents in various colleges and universities in our country and the imbalance in mastering various professional skills have not gained sufficient attention. Most of the animation talents are good at drawing with a variety of artistic skills, but they cannot make overall planning and coordination arrangements and make control and effective design for various animation stories. The lack of storytelling ability makes it difficult for them to complete an animation story by themselves. It is necessary for teachers to cooperate with them in teaching and planning, actively set up workshops with professional talents and then make an animation story from the birth of inspiration to early writing of the script and drawing, as well as story character setting and arrangement. The order of the original painting, sub-scene painting, scene stunt description and positioning and other matters are in need for teachers to guide them little by little. Try to create a relaxed and effective animation production environment so that students learn how to step by step improve their own ability and at the same time learn new ideas of simultaneous development of art skills and literature skills. Coupled with reasonable use of innovative ideas, make the whole process of animation stories creation and completion pleasant with more pioneering and forward-looking, and so on. This is the direction of future colleges and universities cartoon talent development. Their level will directly affect the level of our country's entire animation industry turmoil and new look, so their development and goal are of large vision and need a long way to go.

\section{References}

[1] Wang Dong, Chen Bin. Problems and solutions for animation design talent training in college education under the perspective of innovation [J] Modern Property, 2013, (06): 16-18.

[2] Qi Guihua, Liang Xiao. The present situation of animation talent cultivation in Hebei universities and "external integration" training model exploration [J] Heilongjiang Science and Technology Information, 2013, (05): 191.

[3] Zhu Guijie. Chinese college animation design talent training status analysis [J]. Big Stage, 2011, (09): 238-239.

[4] Su Zhi. College animation design talent training [J]. Art Sea, 2010, (05): 135-136. 